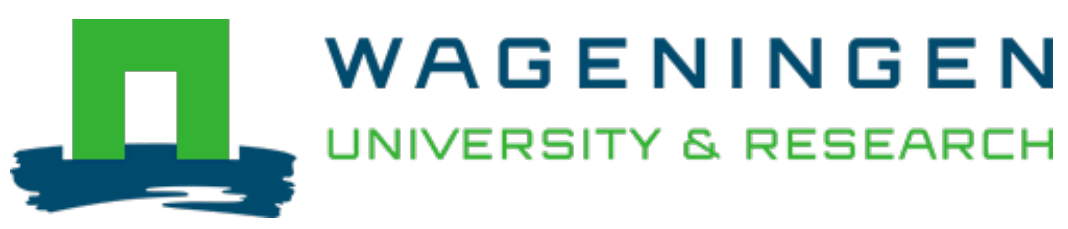

\title{
A systematic review on the impacts of game-based learning on argumentation skills
}

\author{
Entertainment Computing \\ Noroozi, Omid; Dehghanzadeh, Hojjat; Talaee, Ebrahim \\ https://doi.org/10.1016/j.entcom.2020.100369
}

This article is made publicly available in the institutional repository of Wageningen University and Research, under the terms of article $25 \mathrm{fa}$ of the Dutch Copyright Act, also known as the Amendment Taverne. This has been done with explicit consent by the author.

Article 25 fa states that the author of a short scientific work funded either wholly or partially by Dutch public funds is entitled to make that work publicly available for no consideration following a reasonable period of time after the work was first published, provided that clear reference is made to the source of the first publication of the work.

This publication is distributed under The Association of Universities in the Netherlands (VSNU) 'Article $25 \mathrm{fa}$ implementation' project. In this project research outputs of researchers employed by Dutch Universities that comply with the legal requirements of Article $25 \mathrm{fa}$ of the Dutch Copyright Act are distributed online and free of cost or other barriers in institutional repositories. Research outputs are distributed six months after their first online publication in the original published version and with proper attribution to the source of the original publication.

You are permitted to download and use the publication for personal purposes. All rights remain with the author(s) and / or copyright owner(s) of this work. Any use of the publication or parts of it other than authorised under article $25 \mathrm{fa}$ of the Dutch Copyright act is prohibited. Wageningen University \& Research and the author(s) of this publication shall not be held responsible or liable for any damages resulting from your (re)use of this publication.

For questions regarding the public availability of this article please contact openscience.library@,wur.nl 
Review

\title{
A systematic review on the impacts of game-based learning on argumentation skills
}

\author{
Omid Noroozi $^{\mathrm{a}, *}$, Hojjat Dehghanzadeh ${ }^{\mathrm{b}, \mathrm{c}}$, Ebrahim Talaee $^{\mathrm{b}}$ \\ ${ }^{a}$ Wageningen University and Research, the Netherlands \\ ${ }^{\mathrm{b}}$ Tarbiat Modares University, Iran \\ ${ }^{\mathrm{c}}$ Utrecht University, the Netherlands
}

\section{A R T I C L E I N F O}

\section{Keywords:}

Argumentation

Game-based learning

Instructional support

Learning outcomes

\begin{abstract}
A B S T R A C T
This study maps instructional support and learning outcomes of argumentation game-based learning. For this systematic review, 29 publications dating from 2000 through 2019 were studied to highlight the foci of this field of research. Although these studies reported effects of game-based learning on learning outcomes and instructional supports on argumentation skills, none of the publications reported specific instructional support and game elements associated with the learning outcomes. Modeling, reflection and feedback were the most commonly reported instructional support of argumentation game-based learning. Feedback, challenge, and collaboration were the most commonly reported game elements of argumentation game-based learning. In addition, high level of argumentation skills and engagement were the most commonly reported positive learning outcomes of argumentation game-based learning. The results of this study provide suggestions on how to design argumentation game-based learning.
\end{abstract}

\section{Introduction}

Traditional classroom instruction in argument frequently emphasizes basic written composition and use of formal templates overlooking the social aspects that support the development of sophisticated argumentation skills $[85,84]$. Traditional education can no longer meet the needs of the world of work [93]. The new world of work is demanding higher levels of expert thinking and higher-order skills such as argumentation and reasoning [67] but they fail to include relevant evidence or consider alternative perspectives, and they cannot critically evaluate others' arguments $[85,84]$. Therefore, students not only need to acquire and apply new knowledge in their own discipline but also need to acquire essential generic skills such as argumentation, and reasoning in the 21st century [65]. Argumentation skills play an important role in getting one's voice heard in society. These skills help students to justify their reasons for carrying out learning tasks, professional activities, and decisions.

Argumentation has been defined differently in the literature. Argumentation is significant to education due to the importance of discourse in the acquisition of scientific knowledge [68-69]. The process of argumentation is based on the construction and the comparison of arguments (considering attacks or conflicts among them) in order to determine the most acceptable point of view[61]. Argumentation facilitates the grasping of meanings, the comprehension of different perspectives, the resolution of discrepant opinions, the acknowledgment and consideration of other's perspectives, reflection, and the integration of multiple perspectives of the problem at stake [65]. Argumentation is a verbal and social activity of reason aimed at increasing (or decreasing) the acceptability of a controversial standpoint for the listener or reader, by putting forward a constellation of propositions intended to justify (or refute) the standpoint before a rational judge [5]. Argumentation scientific and philosophical discourse and its use are explicitly required in almost every discipline studied in higher education. Developing the ability to argue is recognized as an important goal at elementary, middle, and secondary levels [62] as well as higher education (see [65]).

Despite the use of argumentation in everyday life and also in the social conversation of learner's online exchanges, learners need to learn how to generate valid arguments, reason soundly, and engage in argumentation especially in academic settings [67]. Learning to engage in argumentation is challenging for students due to the complex, nonlinear, and ill-defined nature of argumentation. This is striking since the ability to construct valid arguments and exchange them with others in reasoned debate is one of the critically important real-world skills required in the workplace and community life [65]. There could be several difficulties for students to critically think and engage in

\footnotetext{
* Corresponding author.

E-mail address: omid.noroozi@wur.nl (O. Noroozi).
} 
argumentation. Argumentation is subject to interpretation and in some scenarios, the "facts" may be interpreted differently and are thus not necessarily immutable [82] \& 2013)**. There are situational, emotional, and social barriers that are inherent to argumentation [66]. While some students might hold epistemic emotions (being anxious when receiving counter-arguments), others might be reluctant to oppose and disagree with peers or might not appreciate being challenged themselves [43]. Furthermore, the topic of discussion could play a role, since some students may be emotionally attached to it (e.g. controversial issues like genetically modified food, animal testing or politics), and in such scenarios argumentation may become unfruitful, complicated, or even impossible [6,53]. Many university students never develop more advanced argumentation skills such as identifying and understanding arguments presented in prose and constructing warrants [62]. Liu et al. [56] reported that most of the high school students had difficulties to engage in argumentation either in a collaborative, or individual environment. Students may have difficulties in exploring relevant literature, incorporating the data to make a generalisable claim, using evidence to back their claims, and rebut an argument in light of evidences.

To cope with these challenges, educational technologists have focused on scaffolding students' argumentation. Educational technologies such as ARGUNAUT [60], TagHelper[77], Reason!Able [95], AcademicTalk [59], InterLoc [74], Rashi [27,105], Belvedere [90], and LARGO [70] have used artificial intelligence and language analysis techniques to guide and analyze students' argument moves and support them in training and learning argumentation. It is necessary to utilize instructional scaffolds to enable learners to engage in collaborative discourse and argumentation [80]. However, the potentials of these technological innovations for fostering students' argumentation have not yet been realized in real educational settings. They have remained part of lab experiments without being an explicit and integrated part of the curriculum within a particular discipline (see [29]). A key ingredient that is missing is motivating students to make their argumentation learning to appeal [66]. The importance of argumentation for people's lives, combined with well-documented deficiencies in performance, makes it imperative to use effective educational methods that support the development of argumentation [76].

Designing Game-Based Learning (GBL) environments for fostering students' argumentation skills has recently become popular, especially with respect to scientific results for real-world applications. GBL encourages active learning and engagement by providing learners with the opportunity to place problem-solving scenarios within the context of the play [33]. GBL can promote social interaction [12]. Digital games could be one productive method for developing scientific argumentation skills in a manner aligned with the needs of a 21st-century educational system. Learning sciences community has started to combine design principles of learning games and pedagogical argument scaffolds for enhancing students' argumentation skills. Research on digital GBL with media-enhanced narratives has recently become a topic of interest to learning scientists and educational technologists (e.g. $[1,9,14,20,40,48,58,79])$.

GBL is known to be motivating and engaging to students across various educational levels [26], and they have rapidly become an important area of investigation within technology-enhanced learning environments due to their positive impacts on students' engagement, motivation, and learning (see $[15,20,39,54,57,107]$ ). Many scholars have indicated the potential of digital GBL to support learners in terms of conceptual understanding, process skills and practices, epistemological understanding and player's attitudes identity, and engagement $[20,72,66]$. Therefore, there is a huge demand for application of GBL in various domains such as business, math, statistics, computer science, biology, and psychology [72]. Most of these GBL environments are supposed to help players acquire various 21 st-century skills such as analytical, critical, argumentation, communication, collaboration skills, reasoning, problem-solving, and decision making [14,72,66,86].
Digital games that are designed for learning argumentation typically have various multiple motivational features [24] that can be coupled with technological supports and pedagogical argument scaffolds in order to provide learners with a lot of learning opportunities $[31,66]$. For designing GBL environments for argumentation, the principles of the educational game design need to be combined with pedagogical scaffolds. Scientific evidence suggests that successful games should adhere with design educational principles (see [11,34,36,37,42,72] while placing the emphasis on the elements, features, and rules such as feedback (adaptive feedback), goal structure (cooperative, competitive), intrinsic and extrinsic reward (advance, fail and restart, leaderboard), order rules (simple to complex), role-playing (actors) to also enhance students' motivation and learning.

Furthermore, successful environments for practicing argumentation skills should follow the pedagogical scaffolds (see $[35,46,49,52,92,102])$ while placing the emphasis on individual and group-based supports in terms of reasoning, decision-making, problemsolving, argument structure, construction of complete/sound arguments, construction and refutation of counter-arguments, analysis, extension, and integration of viewpoints to enhance students' argumentation skills. With such combination of the game approach and argumentation design principles, students are expected to appreciate the game in terms of motivation and satisfaction because it provides them with motivational features and entertaining opportunities for the practice and acquisition of various aspects of argumentation skills [66]. Students are also expected to acquire the skills of argumentation because they receive pedagogical scaffolds and corresponding supports that can be practiced repeatedly through a series of argumentation tasks (see $[2,18,96,101]$ ).

Scientific evidence suggests that students' argumentation skills can be facilitated through GBL features and elements such as digital storytelling [109] and computer-supported problem-solving (Şendağ \& Odabaş1, 2009). Over the last two decades, a variety of technological innovations such as online discussion-oriented systems and argument modeling systems have been designed in the form of GBL to scaffold the practice and acquisition of argumentation and skills by guiding students in representing, structuring, reasoning, evaluating, and analyzing arguments (see $[64,83]$ ). The application of such digital GBL for scaffolding argumentation has been realized through digital dialogue games such as AcademicTalk (e.g. [59]), InterLoc (e.g. [74]) and Computer-based Lab for Language Games in Education (CoLLeGE) (e.g. [75]). Most of these powerful digital game environments support improving motivation, hand-eye coordination, and learning about fantasy worlds without a clear real-world connection (see [66]). The extent to which these games and their design principle are successful for the facilitation of students' acquisition of argumentation skills is not yet systematically studied.

Based on argumentation above and also given vast scientific support for the positive impacts of games on various aspects of the learning processes, many researchers from different disciplines are committed to developing GBL to promote students' argumentation skills. Despite various review studies in the field of GBL environments and their effects on various aspects of learning processes and outcomes in different disciplines such as business, marketing, math, statistics, environmental sciences, biology, and psychology (e.g. $[10,21,72,97,108]$ ), no review study has yet been reported for the impacts of the GBL on promotion of students' argumentation skills. It is unclear whether and how these games could influence students' acquisition of argumentation skills. In addition, the field suffers from the lack of a systematic review of the literature in terms of the combination of the design principles of the GBL environments and pedagogical scaffolds and instructional support. Therefore, the main aim of this systematic review study is to clarify what empirical evidence exists with regard to the effects of GBL on students' acquisition of argumentation skills and also to identify successful game design principles, elements and pedagogical scaffolds that align with recognized learning theories. The results of this study could 
provide valuable guidance for educational game designs intended to support students' development of argumentation skills. This review answers the following questions:

1. What is the current state of the art with regard to the use of GBL for the facilitation of argumentation-based learning?

2. Which instructional supports in GBL environments have been investigated for the facilitation of argumentation-based learning?

3. Which game elements in GBL environments have been investigated for the facilitation of argumentation-based learning?

4. Which learning theories in GBL environments have been investigated for the facilitation of argumentation-based learning?

5. Which game genres in GBL environments have been investigated for the facilitation of argumentation-based learning?

6. Which learning outcomes in GBL environments have been investigated for the facilitation of argumentation-based learning?

\section{Method}

\subsection{Search keywords and databases}

A keyword search strategy was used based on the most important concepts of the study, namely GBL and argumentation. First, we identified synonyms and related terms using Merriam-Webster's Online Thesaurus in combination with the reviews of Ke [45], Noroozi et al., [67] as well as Qian and Clark [72]. Then, we combined the related terms with the Boolean operators OR and the three concept areas with AND to arrive at the following search string: game* OR gamification OR GBL OR "game-based learning" OR "serious game" OR "learning games" OR "educational game" OR "entertainment game" OR "video games" OR "mobile game" OR "digital game" OR "edutainment game" AND argument* AND education OR learning OR teaching. To identify relevant publications, a systematic search strategy was executed in the bibliographic databases namely Scopus, ERIC, and Web of Science. Fig. 1 shows the selection process of scientific publications for this systematic review.

\subsection{Criteria for inclusion}

Various inclusion criteria were used to include the most relevant publications. Only peer reviewed published articles with the English language were included in the study as the authors of this study could not understand other languages. To study the most recent literature in the field, the time span was limited to publications from 2000 through 2019. Publications must have covered at least one of the elements of the GBL and one of the elements of the pedagogical argument scaffolds to be included in the review study. This implies that publications which solely focused on GBL or argumentation were excluded from the study. This search yielded 1010 publications. After limiting our search to English peer reviewed publications from 2000 to 2019, only 463 publications remained (238 articles from Scopus, 217 from WoS and 8 articles from Eric databases). Also, the duplicated articles were removed from further screening and analysis $(n=127)$. We then screened titles, abstracts and when necessary the full text of the articles and removed a number of irrelevant publications that did not meet the inclusion criteria. Publications that were excluded from further analysis: (1) did not include evidence related to digital technology enhance environments; (2) did not address both GBL and argumentation in combination, i.e. studies focused only on GBL or argumentation; (3) did not belong to typical educational levels such as primary, secondary, high schools, community college, or higher education; (4) did not report empirical findings for the impacts of GBL on argumentation such as conceptual, methodological, and theoretical publications; (5) did not get published in peer-reviewed journals such as publications as books, book chapters, dissertations, thesis, conference proceedings, reports. Although there are numerous relevant important books, book chapters, conference papers, and dissertations, they were not included in the study because of the lack of information on how the review process has been carried out with these publications. The process of identification of relevant publications was carried out by two coders independently. A kappa statistic was calculated to assess inter-rater reliability between the two coders and was found to be 0.84 . Discrepancies were resolved through discussion with the third coder (the first author of the study) until agreement was reached. Then the coding process started for publications that were included in the final analysis. To assure reliability of the coding process, coding rubrics were created and the coders were trained on the rubrics and the process. Then, both coders independently coded the data. The kappa statistics for the coding procedure between the two coders was in average 0.86 (ranging from 0.73 to 0.96 ) for different categories of the data. Discrepancies were resolved through discussion with the third coder. The search strategy was not restricted to a single discipline of interest. Fig. 1 shows the process of selecting publications. In total, the 29 articles matched our search criteria and used in the final analysis. A complete list of publications and quantitative descriptions can be seen in Table 1.

\section{Results}

\subsection{The current state of the art for the use of GBL for argumentation}

Table 1 provides an overview of the included publications in terms of authors, year of publications, journals, subjects, the number of participants, group sizes, educational levels, platforms, instructional supports, game design elements, game genres, learning theories, research focuses, p-value, effect size, and main findings. This table indicates that the use of GBL for argumentation is still limited with only 29 articles that matched our research criteria. Various types of digital GBL environments (e.g. InterLocl, Earthquake, The Golden Hour, Mystery of Taiga River, CPGame, Seattle Sea-Level Rise, Edmodo, OGSA, GBI, iAbstract, Chess, Policy World, Bitstrips, CoLLeGE, Reason Racer, Seaball, Mad City Mystery, World of Warcraft, ANYCaRE, E-game, Al Chemist Knight, Geniverse, Muslim community) have been used to gamify argumentation which indicate that learning argumentation skills can easily be gamified with game elements in digital environments. GBL environments for argumentation were mostly used for science with 12 frequencies followed by biology (3), biotechnology (2), nursing (2), English (1), engineering (1), Intercultural education (1), academic reading (1), STEM (1), mathematic (1), philosophy (1), kinematics (1), management (1), and chemistry (1). In terms of educational level, most GBL environments for argumentation were used in high schools with eighteen frequencies followed by higher education (8), and elementary school (2). In terms of platform, most GBL environments were used from Reason Racer with four frequencies followed by InterLoc (2), Seaball (2). Argumentation (18), scientific reasoning skills (2), academic summarization and reading (1), argumentation and logic (1), socio-scientific reasoning and argumentation (2), argumentation and thinking (2), attitudes, knowledge, and argumentation (1), argumentation and inquiry skills (1), argumentation, knowledge, and decision-making (1), scientific competencies (1), and analyzing arguments, asking questions and answering (1) were respectively the most commonly used type of research focuses for studying GBL for argumentation. The methodology of the included publications varied in terms of the number of participants ranging from only ten up to 979 participants.

\subsection{Instructional supports for GBL for argumentation}

The reviewed publications used a variety of instructional supports for argumentation in GBL environments. The most commonly used instructional supports for argumentation were modeling (11), reflection (6), interactivity (2), and feedback (2). The least frequently used instructional supports for learning argumentation though GBL in digital 


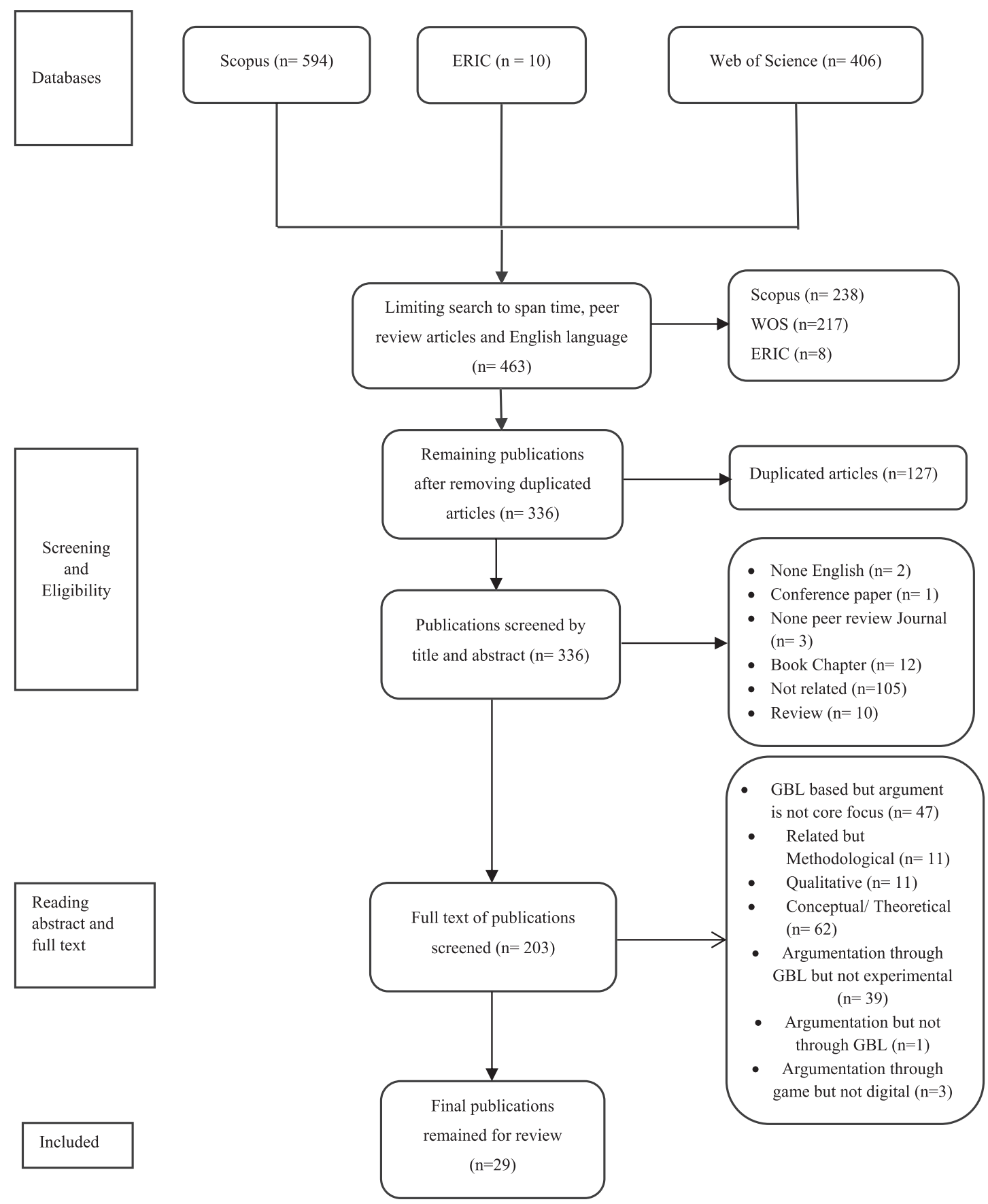

Fig. 1. Flowchart process selection.

environments were adaptivity (1), assignment (1), collaboration (1), contextualization (1), modality (1), narrative (1), and pedagogical agent (1). Table 2 presents a specific overview of the instructional supports and their frequencies used for GBL for argumentation in the reviewed publications.

\subsection{Game elements for GBL for argumentation}

Further analysis of the 29 studies indicates that game design elements were specifically targeted in the choice of game, and all studies included more than one game design element. Additionally, half of the studies utilized pre-existing games (video games, serious games, simulations, augmented reality and design focused games), and the rest designed a game specific to their study. The reviewed publications used a variety of game elements (both dynamics and mechanics) for argumentation in digital GBL environments. The most commonly used elements for argumentation GBL were feedback (27), challenge (14), collaboration (10), point (10), competition (7), character (5), goal (5), interaction (5), social (5), avatar (4), exploration (4), level (4), rule (4), story (4), score (4), timed performance (4), time pressure (4). The least frequently used elements for argumentation GBL were an apprentice (1), assistance (1), battling (1), bonus (1). Table 3 presents an overview of the game elements and the frequency of each game element in the reviewed articles.

\subsection{Learning theories for GBL for argumentation}

Table 4 indicates that some learning theories used in the GBL for argumentation. The most commonly used theories were socio-conflict (5), social-cognitive learning (3), cognitive (3), experiential learning. 


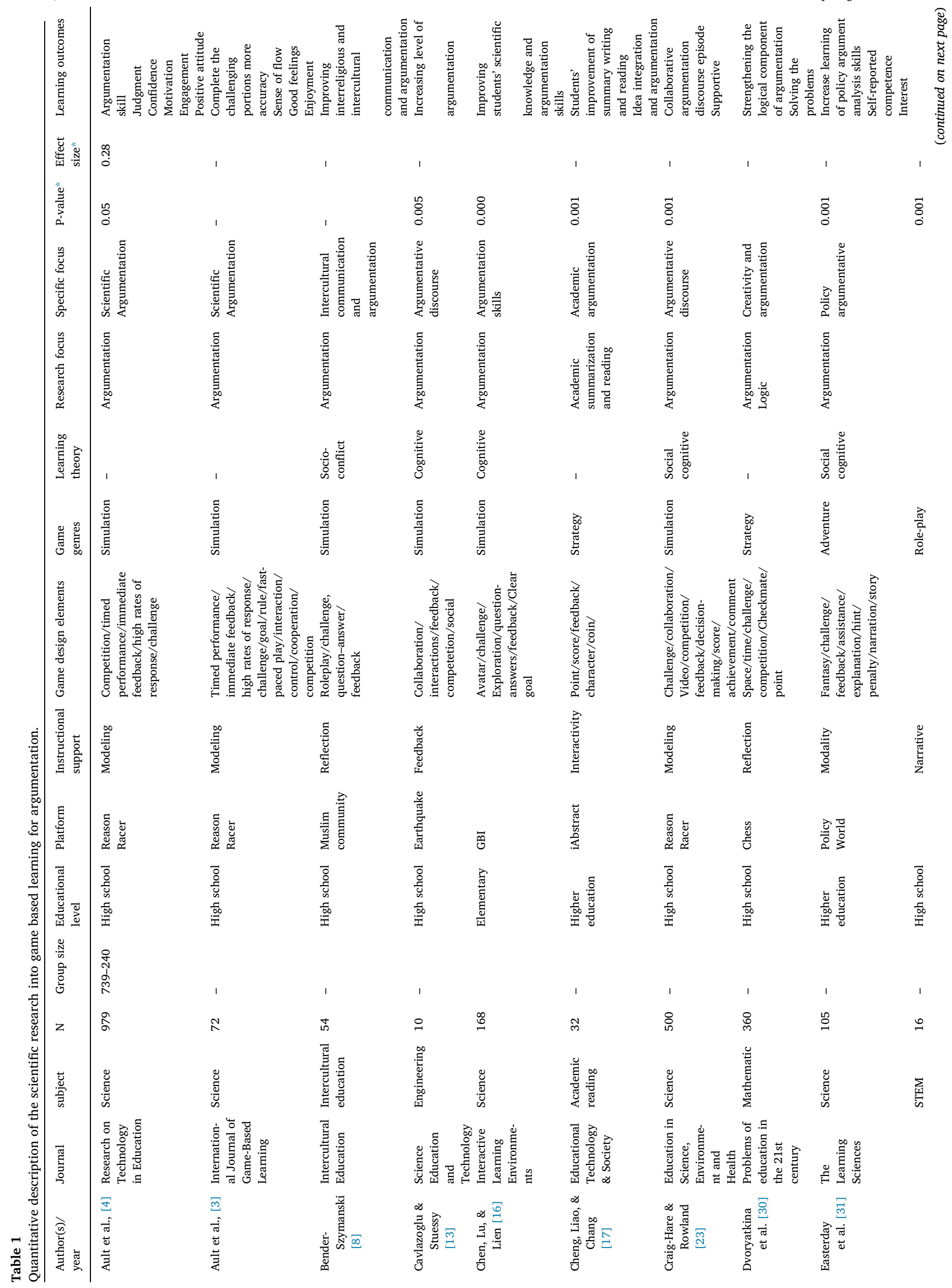




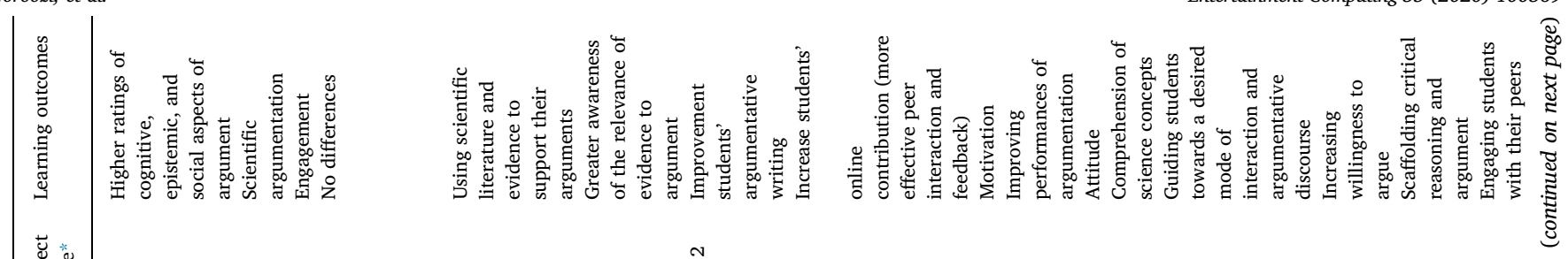
苞思

总

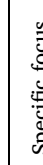

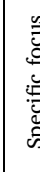

竞

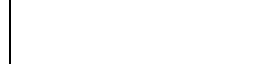

1 1 กี

营

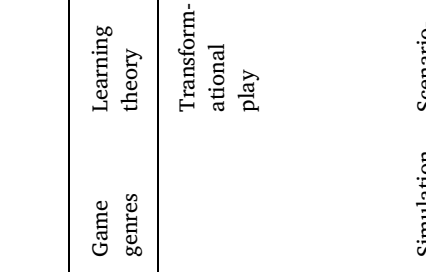

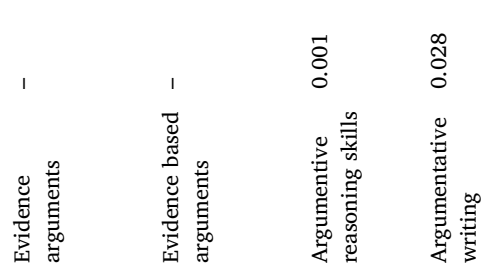

Бั

莬

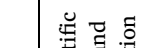

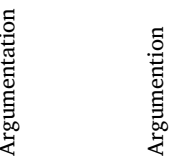

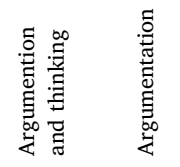

In

翌

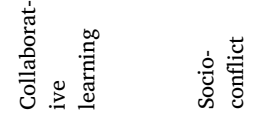

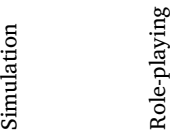

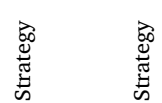

总

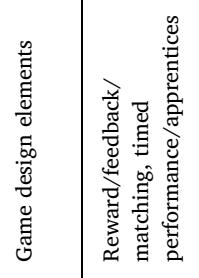

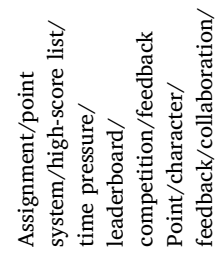

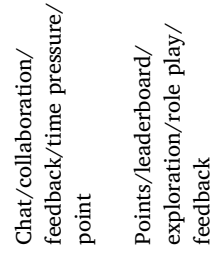

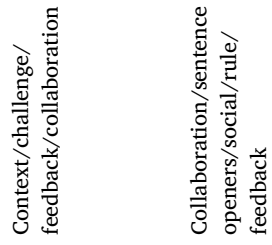

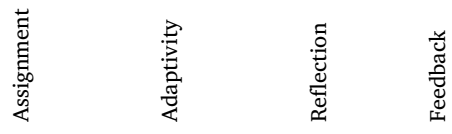

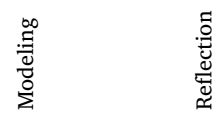

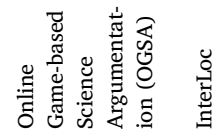

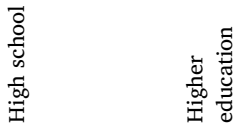

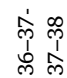

สำ के

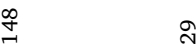

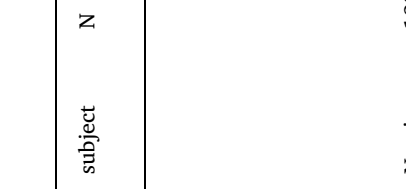

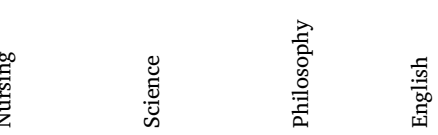

:

竞

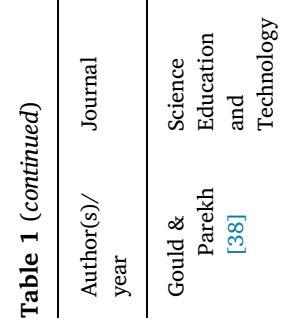

iII II

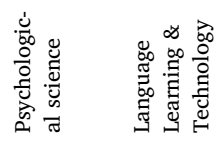

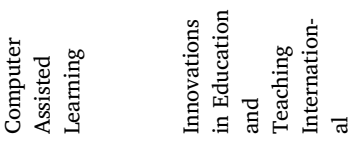

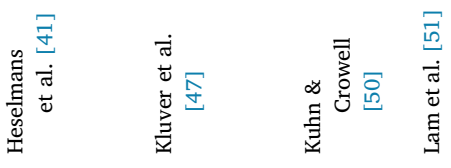

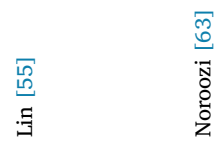




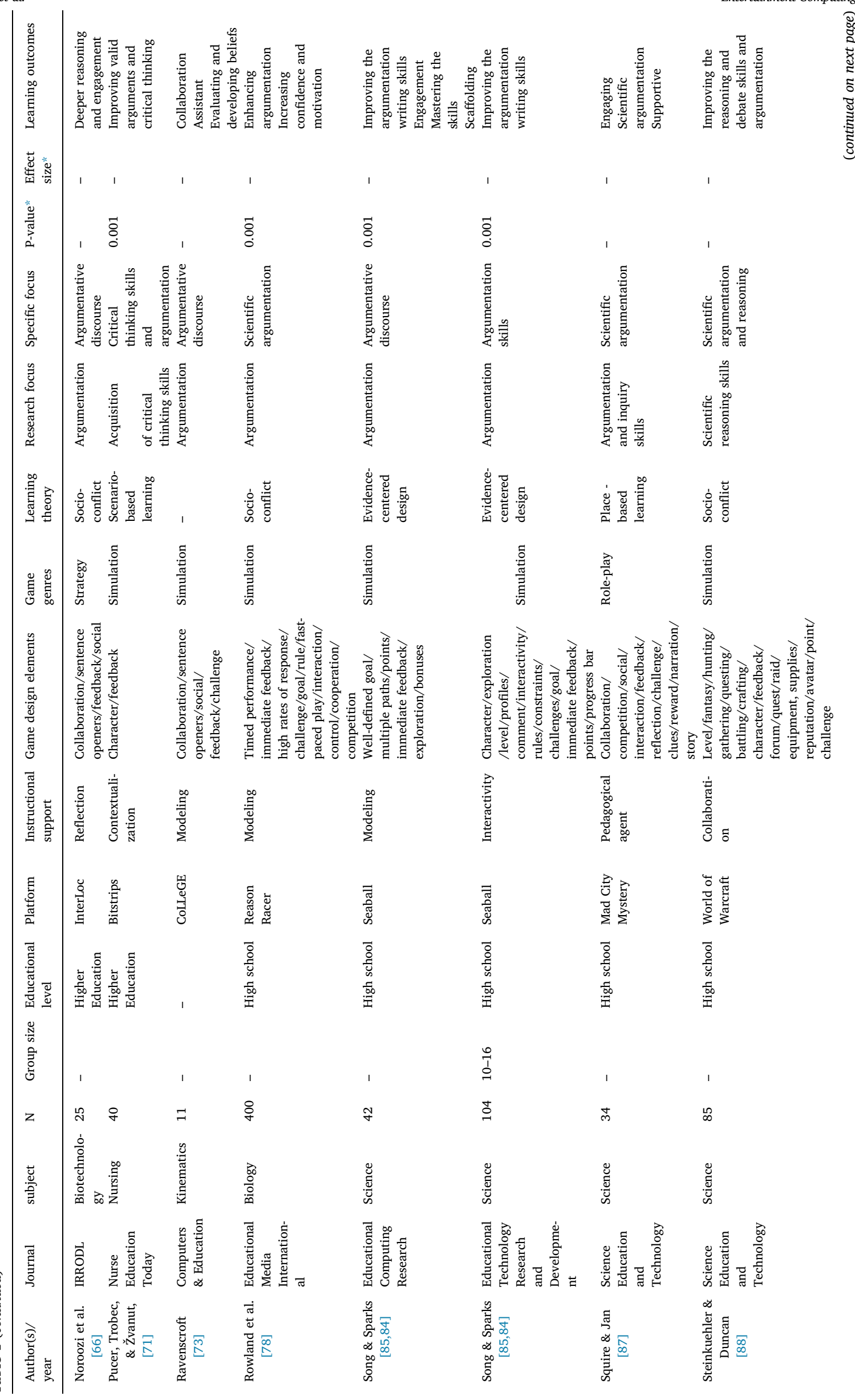




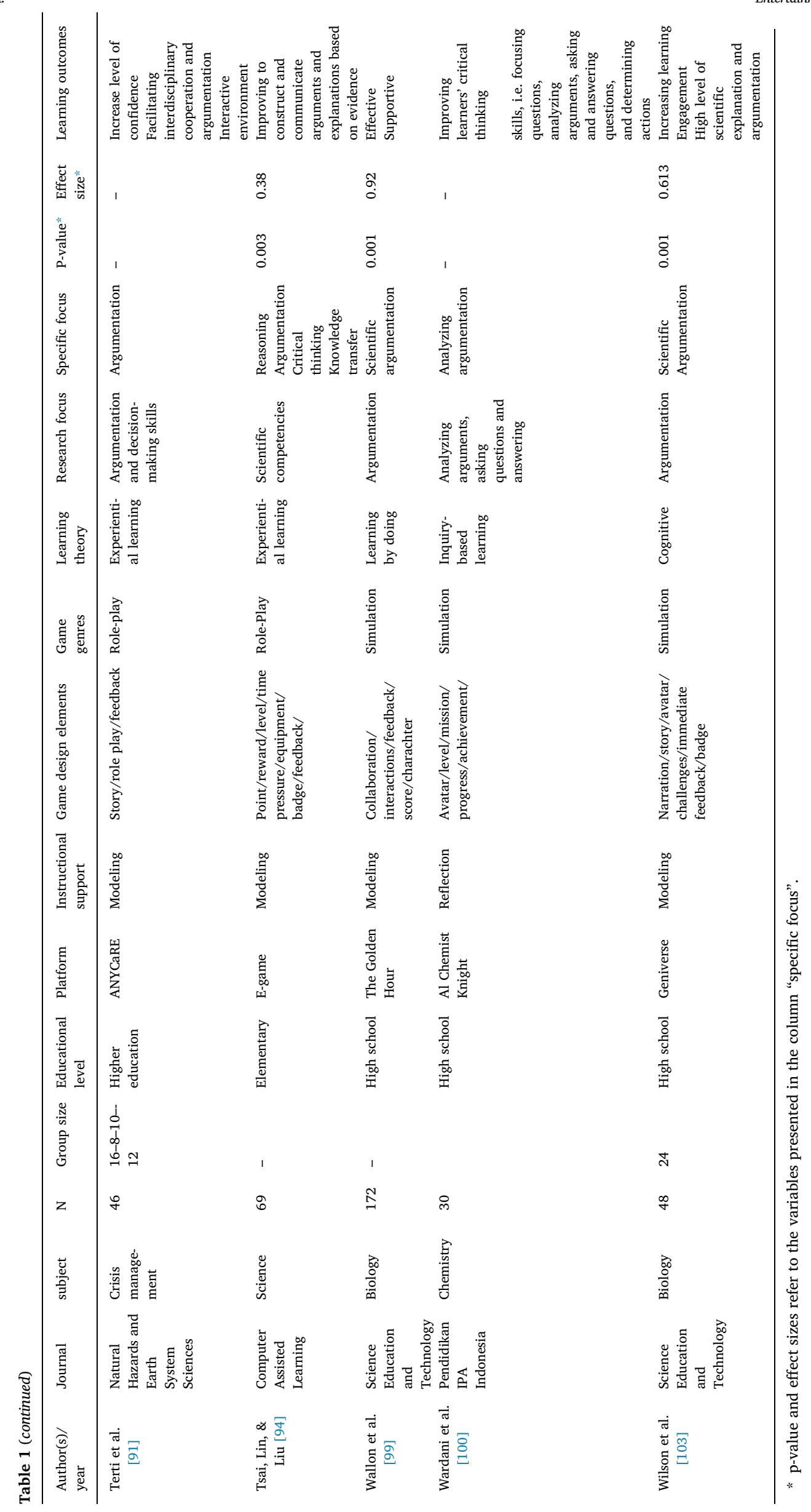


Table 2

The instructional support used in games for argumentation.

\begin{tabular}{|c|c|c|}
\hline Type of instructional support & Frequency $(\mathrm{N})$ & Description \\
\hline Modeling & 11 & Describing how a problem is solved \\
\hline Reflection & 6 & Stimulation to think about answers and/or explain these answers \\
\hline Feedback & 2 & Information whether an/or why an answer is correct \\
\hline Interactivity & 2 & The game is responsive to the player's actions \\
\hline Adaptivity & 1 & Match the game to the success of the player \\
\hline Assignment & 1 & Prompts to explore the relationships between variables \\
\hline Collaboration & & Discussion that often seeks to explain implicit knowledge \\
\hline Contextualization & 1 & Providing learning in a meaningful setting \\
\hline Modality & 1 & The use of the audio channel to limit visual search \\
\hline Narrative & 1 & Story line that can help players to organize educational material \\
\hline Pedagogical agent & 1 & An agent gives hints to help the student to learn from the game \\
\hline
\end{tabular}

The least frequently used learning theories on games for improving argumentation were collaborative learning (1), dialogue theory (1), inquiry- based learning (1), and learning by doing (1). And, six articles did not report any learning theory for the use of GBL for argumentation. Table 4 presents a specific overview of the theories and their frequencies used in GBL environments for improving argumentation.

\subsection{Game genres for GBL for argumentation}

The reviewed publications used a variety of game genres for the use of GBL environments for the facilitation of argumentation skills. The most commonly used game genres for argumentation were simulation (17), strategy (6), and role-play (5). The least frequently used game genres was adventure (1). Table 5 presents a specific overview of the game genres and the frequency of each game genres with a description that is used for gamifying argumentation through GBL environments in the reviewed publications.

\subsection{Learning outcomes for GBL for argumentation}

Table 6 shows the common learning outcomes of GBL for argumentation. The reviewed publications reported a variety of learning outcomes for argumentation skills in game-based learning environments. The most commonly used learning outcomes for the use of GBL for argumentation were improving the high level of argumentation skills (17), engagement (7), increasing confidence (3), increasing critical thinking (3), improving students' scientific

knowledge (3), and motivation (3). The least frequently reported learning outcomes for the use of GBL for argumentation were assistant (1), enjoyment (1), evaluating and developing beliefs (1), facilitating interdisciplinary cooperation (1), good feelings (1), and greater awareness of the relevance of evidence to argument (1).

\section{Discussions}

This systematic review aimed to provide readers with the current state of the art on the use of GBL for the facilitation of argumentation skills. To do so, a specific search strategy was conducted with relevant keywords from different databases which resulted in 29 publications to be included in this systematic review. We then analyzed these publications from different perspectives and provided a quantitative description of scientific research into this field of research. The reviewed publications showed that GBL environments have been used for improving various aspects of argumentation (see $[23,55,66]$ ). Most studies on this field of research have been published recently with a rising number from the latest years. Such rise of the use of GBL environments in recent years could be attributed to the growing popularity of this field and certain benefits it could bring to the facilitation of argumentation.

Our review showed that the reviewed publications of GBL for argumentation are quite diverse in terms of subject, platform, and sample size. Research on GBL for argumentation has attracted research scholars with various types of subject (e.g. biotechnology, English, management, science, STEM, philosophy, nursing), different types of platform (e.g. InterLocl, Earthquake, The Golden Hour, Edmodo, Mystery of Taiga River, SeaBall, CPGame, Seattle Sea-Level Rise, Reason Racer, OGSA,

Table 3

The game elements used for argumentation.

\begin{tabular}{|c|c|c|c|c|c|}
\hline Game elements & Frequency $(\mathrm{N})$ & Game elements & Frequency (N) & Game elements & Frequency $(\mathrm{N})$ \\
\hline Feedback & 27 & Challenge & 14 & Collaboration & 10 \\
\hline Point & 10 & Competition & 7 & Character & 5 \\
\hline Goal & 5 & Interaction & 5 & Social & 5 \\
\hline Avatar & 4 & Exploration & 4 & Level & 4 \\
\hline Rule & 4 & Story & 4 & Score & 4 \\
\hline Timed performance & 4 & Time pressure & 4 & High rate of response & 3 \\
\hline Narration & 3 & Reward & 3 & Role play & 3 \\
\hline Sentence opener & 3 & Achievement & 2 & Badge & 2 \\
\hline Collect items & 2 & Comment & 2 & Control & 2 \\
\hline Cooperation & 2 & Equipment & 2 & Fantasy & 2 \\
\hline Leaderboard & 2 & Progress bar & 2 & Question-answer & 2 \\
\hline Apprentice & 1 & Assistance & 1 & Battling & 1 \\
\hline Bonus & 1 & Chat & 1 & Checkmate & 1 \\
\hline Clue & 1 & Constraint & 1 & Context & 1 \\
\hline Crafting & 1 & Decision making & 1 & Explanation & 1 \\
\hline Fast paced play & 1 & Forum & 1 & Hint & 1 \\
\hline High-score list & 1 & Hunting & 1 & Demo & 1 \\
\hline Matching & 1 & Mission & 1 & Multiple path & 1 \\
\hline Penalty & 1 & Profile & 1 & Quest & 1 \\
\hline Raid & 1 & Reflection & 1 & Reputation & 1 \\
\hline Space & 1 & Supplies & 1 & Video & 1 \\
\hline
\end{tabular}


Table 4

The dominant theories used for game-based argumentation.

\begin{tabular}{|c|c|c|c|}
\hline Learning theory & Frequency $(\mathrm{N})$ & Description & References \\
\hline Socio-conflict & 5 & $\begin{array}{l}\text { This theory argues that individuals and groups (social classes) within society } \\
\text { interact on the basis of conflict rather than consensus. }\end{array}$ & $\begin{array}{l}\text { Steinkuehler \& Duncan [88], Rowland et al. [78], } \\
\text { Noroozi et al. [66], Noroozi [63], Bender- } \\
\text { Szymanski [8] }\end{array}$ \\
\hline Cognitive theory & 3 & $\begin{array}{l}\text { Cognitive learning theory implies that the different processes concerning } \\
\text { learning can be explained by analyzing the mental processes first. It posits that } \\
\text { with effective cognitive processes, learning is easier and new information can } \\
\text { be stored in the memory for a long time. }\end{array}$ & $\begin{array}{l}\text { Cavlazoglu \& Stuessy [13], Chen, Lu, \& Lien } \\
\text { [16],Wilson et al. [103] }\end{array}$ \\
\hline Social cognitive learning & 3 & $\begin{array}{l}\text { A theory of learning process and social behavior which proposes that new } \\
\text { behaviors can be acquired by observing and imitating others. }\end{array}$ & $\begin{array}{l}\text { Lam et al. [51], Easterday et al. [31], Craig-Hare } \\
\text { \& Rowland [23] }\end{array}$ \\
\hline $\begin{array}{l}\text { Experiential learning } \\
\text { theory }\end{array}$ & 2 & $\begin{array}{l}\text { Experiential learning is the process of learning through experience, and is more } \\
\text { specifically defined as "learning through reflection on doing". Hands-on } \\
\text { learning is a form of experiential learning but does not necessarily involve } \\
\text { students reflecting on their product. }\end{array}$ & Terti et al. [91],Tsai, Lin, \& Liu [94] \\
\hline Evidence-centered design & 2 & $\begin{array}{l}\text { A "principled framework for designing, producing, and delivering educational } \\
\text { assessments" }\end{array}$ & Song \& Sparks $[85,84]$, Song \& Sparks $[85,84]$ \\
\hline Scenario-based learning & 2 & $\begin{array}{l}\text { Scenario-based learning (SBL) uses interactive scenarios to support active } \\
\text { learning strategies such as problem-based or case-based learning. }\end{array}$ & $\begin{array}{l}\text { Pucer, Trobec, \& Žvanut, [71]; Heselmans et al } \\
\text { [41] }\end{array}$ \\
\hline Collaborative learning & 1 & $\begin{array}{l}\text { An educational theory to teaching and learning that involves groups of } \\
\text { students working together to solve a problem, complete a task, or create a } \\
\text { product. }\end{array}$ & $\operatorname{Lin}[55]$ \\
\hline Dialogue theory & 1 & $\begin{array}{l}\text { In dialogue theory, meaning is discovered through responses to narratives and } \\
\text { emergent questions within historical existence, which arbitrate demands } \\
\text { within a proximate dialogic occasion. }\end{array}$ & Kuhn \& Crowell [50] \\
\hline Inquiry-based learning & 1 & $\begin{array}{l}\text { Inquiry-based learning is a form of active learning that starts by posing } \\
\text { questions, problems or scenarios. }\end{array}$ & Wardani et al. [100] \\
\hline Learning by doing & 1 & $\begin{array}{l}\text { learner learn by touching and doing. You understand and remember things } \\
\text { through physical movement (touching, moving, building, or drawing). }\end{array}$ & Wallon et al. [99] \\
\hline Place-based learning & 1 & $\begin{array}{l}\text { An theory to learning that takes advantage of geography to create authentic, } \\
\text { meaningful and engaging personalized learning for students. }\end{array}$ & Squire \& Jan [87] \\
\hline Transformational play & 1 & $\begin{array}{l}\text { Transformational play involves positioning students as empowered actors who } \\
\text { must understand and enlist academic content in order to effectively transform } \\
\text { problematic scenarios. }\end{array}$ & Gould \& Parekh [38] \\
\hline
\end{tabular}

Policy World, Geniverse, CoLLeGE, ANYCaRE, iAbstract), and small to large number of participants. Such diversity might be due to the impetus to thoroughly explore the potential of GBL for argumentation. GBL for argumentation has been applied in different educational levels ranging from elementary to higher education. However, this field of research has not been very popular in elementary schools with a small number of articles. This diversity implies that research in this field of research and the use of GBL for argumentation is likely to be promising in the coming years.

Next, we focused our attention on the type of game elements that have been used for GBL for argumentation. Although various game elements have been used in GBL environments for argumentation, there was not a specific pattern as to what types of game elements can be most useful for what aspects of argumentation skills. The most commonly used elements for argumentation GBL were the presence of feedback. This is not surprising as feedback is a powerful tool that is used frequently for various purposes, for example, for the development of students' argumentation, critical thinking, reasoning behavior (see $[66,65,67])$, and gamifying English language [25]. After feedback, challenge and collaboration were most used game elements on various GBL environments for improving argumentation skills. Challenge and collaboration have been used as game-design elements to engage players in social interactions that lead to persistence in game play. Welldesigned GBL environments pose various challenges that encourage collaborative problem solving [72]; thereby giving individuals opportunities to develop 21st-century skills. This issue shows that interaction between students in small groups and social relationships is important for the quality of argumentation skills in various subjects [99]. Of course, with quantifying game elements, one must consider that some of the game elements might naturally occur more than other game elements in GBL environments. For example, feedback and collaboration are the game elements that used in almost any GBL environments while other elements such as penalty might be quite specific and thus might not be a common element for the use in GBL environments.

In addition, challenges in games increase learners' engagement during argumentation and make them reflect on process or augmenting and reasoning [87]. In games, things that are too easy or too difficult will not pique our interest, as they lead to boredom or frustration, respectively. The optimal amount of difficulty or challenge should match the user's abilities to the skills required to accomplish each goal. Ideally, the optimal amount of challenge embedded in a game should create "motivational tension" [28]. In other words, motivation is maintained by creating uncertainty about goal attainment. Uncertain outcomes are challenging because of the variability depending on the user's actions, multiple goals, hidden information, and randomness. Research has shown that challenge is correlated with both intrinsic and "effectance" motivation (i.e. the desire to foster competence and efficacy) [104].

Table 5

The game genres used for argumentation.

\begin{tabular}{|c|c|c|}
\hline Game genre & Frequency $(\mathrm{N})$ & Description \\
\hline Simulation & 17 & Approximate imitation of the operation of a process or system, situation \\
\hline Strategy & 6 & A type of game that emphasizes skillful thinking and planning to achieve a goal. \\
\hline Role-play & 5 & A type of game that players get roles of characters in a fictional or real setting. \\
\hline Adventure & 1 & A type of video game in which the participant plays a fantasy role in an episodic adventure story. \\
\hline
\end{tabular}


Table 6

The learning outcomes of GBL for argumentation.

\begin{tabular}{|c|c|c|}
\hline Learning outcomes & Frequency $(\mathrm{N})$ & Study \\
\hline Improving high level of argumentation skills & 17 & $\begin{array}{l}\text { Ault et al. [4], Bender-Szymanski [8], Cavlazoglu \& Stuessy [13], Chen, Lu, \& Lien [16], } \\
\text { Easterday et al. [31], Lam et al. [51], Lin [55], Noroozi [63], Pucer, Trobec, \& Žvanut, [71], } \\
\text { Rowland et al. [78], Song \& Sparks [85,84], Song \& Sparks [85,84], Squire \& Jan [87], } \\
\text { Steinkuehler \& Duncan [88], Tsai, Lin, \& Liu [94], Wilson et al. [103] }\end{array}$ \\
\hline Engagement & 7 & $\begin{array}{l}\text { Ault et al. [4], Gould \& Parekh [38], Noroozi [63], Noroozi et al. [66], Song \& Sparks } \\
\text { [85,84], Wilson et al. [103], Squire \& Jan [87] }\end{array}$ \\
\hline Increasing confidence & 3 & Ault et al. [4], Rowland et al. [78], Terti et al. [91] \\
\hline Increasing critical thinking & 3 & Noroozi [63], Pucer, Trobec, \& Žvanut, [71], Wardani et al. [100] \\
\hline Improving students' scientific knowledge & 3 & Chen, Lu, \& Lien [16], Lin [55], Wilson et al. [103] \\
\hline Motivation & 3 & Ault et al. [4], Lam et al. [51], Rowland et al. [78] \\
\hline More supportive & 3 & Craig-Hare \& Rowland [23], Squire \& Jan [87], Wallon et al. [99] \\
\hline Collaborative learning & 2 & Craig-Hare \& Rowland [23]; Ravenscroft [73] \\
\hline Deep logical reasoning & 2 & Noroozi [64]; Steinkuehler \& Duncan [88] \\
\hline Positive attitude & 2 & Ault et al. [4], Lin [55] \\
\hline Assistant with argumentation sentence construction & 1 & Ravenscroft [73] \\
\hline $\begin{array}{l}\text { Complete the challenging portions more quickly and more } \\
\text { accuracy }\end{array}$ & 1 & Ault et al. [3] \\
\hline Effective & 1 & Wallon et al. [99] \\
\hline Enjoyment & 1 & Ault et al. [3] \\
\hline Evaluating and developing beliefs & 1 & Ravenscroft [73] \\
\hline Facilitating interdisciplinary cooperation & 1 & Terti et al. [91] \\
\hline $\begin{array}{l}\text { Focusing questions, analyzing arguments, asking and answering } \\
\text { questions, and determining actions }\end{array}$ & 1 & Wardani et al. [100] \\
\hline Good feelings & 1 & Ault et al. [3] \\
\hline Greater awareness of the relevance of evidence to argument & 1 & Kuhn \& Crowell $[50]$ \\
\hline $\begin{array}{l}\text { Higher ratings of cognitive, epistemic, and social aspects of } \\
\text { argument }\end{array}$ & 1 & Gould \& Parekh [38] \\
\hline Idea integration and argumentation & 1 & Cheng, Liao, \& Chang [17] \\
\hline Improving interreligious and intercultural communication & 1 & Bender-Szymanski [8] \\
\hline Increasing willingness to argue & 1 & Noroozi $[63]$ \\
\hline Increasing online contribution & 1 & Lam et al. [51] \\
\hline Interactive environment & 1 & Terti et al. [91] \\
\hline Increasing interest in the subject & 1 & Easterday et al. [31] \\
\hline Judgment & 1 & Ault et al. [4] \\
\hline Mastering the skills & 1 & Song \& Sparks $[85,84]$ \\
\hline Peer interaction & 1 & Lam et al. [51] \\
\hline Scaffolding & 1 & Song \& Sparks $[85,84]$ \\
\hline Sense of flow & 1 & Ault et al. [3] \\
\hline Self-reported competence & 1 & Easterday et al. [31] \\
\hline Solving the problems & 1 & Dvoryatkina et al. [30] \\
\hline Strengthening the logical component of argumentation & 1 & Dvoryatkina et al. [30] \\
\hline Students' improvement of summary writing and reading & 1 & Cheng, Liao, \& Chang [17] \\
\hline $\begin{array}{l}\text { Using scientific literature and evidence to support their } \\
\text { arguments }\end{array}$ & 1 & Kluver et al. [47] \\
\hline
\end{tabular}

We also explored instructional support of GBL for argumentation. Modeling [4,3,23,55,73,85,84,91,94,99,103], feedback [51], interactivity $[17,85,84]$, and reflection $[8,30,50,66,63,100]$ were the most commonly reported instructional supports of the GBL for argumentation. This is reflected in the analysis of different types of instructional supports. Especially, adaptivity (match the game to the success of the player), assignment (prompts to explore the relationships between variables), modeling (showing which information is important in order to solve a problem and how to solve a problem), modality (the use of the audio channel for verbal explanations to limit visual search), feedback (information whether and/or why an answer is correct), and contextualization (providing learning in a meaningful setting), pedagogical agent (an agent gives hints to help the student to learn from the game), and collaboration (discussion that often seeks to explain implicit knowledge) are effective techniques to support learners in selecting relevant information [106]. It confirms that the use of instructional supports in GBL can improve learning. With regard to multimedia learning environments, various analyses have shown that well-designed instructional supports (e.g. modeling, interactivity, modality, feedback, contextualization, pedagogical agent, narrative) improve learning because they help learners refrain from ineffective use of cognitive capacity [106].

A further review of the 29 articles indicates that 23 referenced one learning theory as a theoretical framework. The most commonly referenced theoretical foundations were socio-conflict, and social cognitive theories. Both merge nicely with the naturalistic game play as learning takes place when it is social, active, and situated (e.g., [98]). Socio-scientific content-based scenarios address issues that are personally meaningful and engaging to students. Components of socioscientific content-based scenarios address for argumentation provide a structure for students to discuss contentious topics in a productive and meaningful mannerCraig-Hare et al. [23]. Next, to this, GBL environments also targeted other learning theories (e.g. cognitive learning, collaborative learning, and experiential learning). Also, according to Qian and Clark [72], GBL is more likely to yield positive outcomes when learning theories are incorporated into the design. Fortunately, the present study shows that most of the 29 articles targeting argumentation skills as learning outcomes designed their GBL environments based on existing learning theories. The challenge for instructional designers is the complex task of designing a game with the goal of intentional instruction [7] without alienating the players by inserting overt academic content or stressing learning outcomes that do not blend seamlessly with the game mechanics.

One of the shortcomings of the use of GBL for facilitation of argumentation is that most studies did not follow specific learning theories. Only few studies revealed their learning theories for designing the GBL environments. This implies that such GBL environments in future research should indicate their learning theories so that people know what 
learning theories can be matched with what aspects of games and also what learning theories can be used in the design of GBL environments to facilitate specific aspects of the learning outcomes.

Furthermore, most reviewed publications referred to game genres such as simulation, role-play, strategic and the least used game genre was adventure (see $[4,3,8,17,23,30,31,47,55,66,85,84,99]$ ). The finding of the reviewed articles showed that GBL lead leaners to have a positive attitude towards argumentation skills and learn argumentation and reasoning. Finally, such diverse targeted research findings of publications reported to the potential benefits of the GBL for argumentation.

Finally, improving students' high level of argumentation skills, engagement, confidence, critical thinking, scientific knowledge, and motivation were the most commonly reported positive learning outcomes of the GBL for argumentation (see Table 6). GBL environments were hypothesized to aid instructional purposes because they theoretically provide diverse approaches that can address cognitive and effective learning, interactivity, and, perhaps most critically, motivation for learning. According to Jung et al. [44], when users were given a clear goal, their engagement increased in contrast to individuals who were told to simply do their best or those who were not given an explicit goal. These results also contribute to the evidence that educational games can provide increasing amounts of practice in an engaging environment and have the potential to result in improved performance. The importance of practice in learning a specific skill, to the point of transfer, is well founded [4]. The most important challenge in the reviewed publication is that the underlying design principles, game elements, and the learning theories for achieving such learning outcomes are not defined. As a result, it is not clear what learning theories and what game elements can be most beneficial for each specific learning outcomes. Future research could delve into this and further inform game designers in this respect.

\section{Conclusion, limitations, and suggestions for future research}

This systematic review presents an overview of the current state of the art on the use of GBL for the facilitation of argumentation skills in digital learning environments. Specifically, this study maps instructional support and learning outcomes of argumentation. Feedback, challenge, and collaboration were the most commonly reported game elements of argumentation GBL. Such timely systematic review is indeed needed because GBL environments for argumentation have started to become a promising field that attracts both researchers, scholars, and teachers who are keen to teach argumentation in different subjects. It provides interested scholars with information on how to take advantage of the potential benefits of GBL for argumentation and how to design digital environments to improve students' argumentation-based learning processes and their corresponding learning experiences and outcomes.

The current systematic review shows that publications on GBL and argumentation were mostly conducted on high school and higher education levels, while there are small experimental researches in this field on elementary schools. More empirical research is needed to see how and the extent to which GBL environments can be designed for facilitation of argumentation skills of elementary school pupils.

This systematic review covers a selected time span, language, variety of relevant databases, and adopted a search strategy that provides a moderate representation of this field of research. The focus of this study is on the use of GBL for argumentation. Future research could, therefore, present the current state of the art with regard to the use of GBL for other 21-century skills (e.g. critical thinking, problemsolving, collaborative learning). This would enable scholars to discover the potential benefits, advantages, and disadvantages of every single type of game and thus provide suggestions on when and how to use them for various 21-century skills.

Although most publications used specific instructional supports for the use of GBL for argumentation, none of the included articles has reported which instructional supports can exclusively be used for improving which specific aspects of argumentation skills. It is not clear what instructional supports are more effective for various aspects of the learning argumentation. One direction for future research is to tackle this issue and investigate how every single instructional support at a micro level could contribute to each aspect of the argumentation skills. This could be done through an empirical study that would combine different instructional supports and compare their outcomes and functions.

Although most of the included publications reported game elements, none of them reported which game element is more effective for teaching argumentation. Follow-up research is needed to shed light on this issue. This could be done through an empirical study that would combine similar game elements and compare them with other game elements with different functions and purposes.

We did not report common affordances and hindrances that are inherent to GBL environments for argumentation skills. Gamified environments typically provide learners with various affordances that can be used with the help of ICT tools (see [22]). More research is needed to shed light on the possible affordances and hindrances that are inherent to the use of GBL for argumentation.

In this article, we conceptually provided links among various aspects of the GBL environments (i.e. game design, game elements, game genres) and different aspects of argumentation-based learning (i.e. argumentation skills, argumentation knowledge, and argumentation attitude). Such links are highly desirable and can provide the necessary foundation for future research on the effectiveness of GBL for argumentation skills. This review might have practical implications for game developers, content designers, and evaluators. For example, developers could create products that directly lead to specific learning outcomes and market their products accordingly. Designers could select appropriate game characteristics based on desired learning outcomes and incorporate the specific game attributes into their instruction. Finally, evaluators could easily focus on proven measures that target the specific learning outcomes that a game has been designed to elicit. These findings are useful to commercial game developers, because the engagement potential of a GBL is important for game development, with the goal of establishing a compulsion to play. Typical educational game developers, however, do not take advantage of the potential of GBL to engage students through the creation of a sense of flow with game mechanics that are distinct from the content addressed in the game. The implication for educational game development is whether similar types of activities, ones that are not related to content but specifically designed to heighten emotional attachment and a sense of flow, should be considered an integral part of games that are designed for students to practice complex and difficult skills.

\section{Declaration of Competing Interest}

The authors declare that they have no known competing financial interests or personal relationships that could have appeared to influence the work reported in this paper.

\section{Appendix A. Supplementary material}

Supplementary data to this article can be found online at https:// doi.org/10.1016/j.entcom.2020.100369.

\section{References}

[1] A.I. Abdul Jabbar, P. Felicia, Gameplay engagement and learning in game-based learning: A systematic review, Rev. Educ. Res. 85 (4) (2015) 740-779.

[2] J.E. Andriessen, M.J. Baker, Arguing to learn, in: R.K. Sawyer (Ed.), The Cambridge Handbook of the Learning Sciences, Cambridge University Press, New York, NY, 2015, pp. 439-460. 
[3] M. Ault, J. Craig-Hare, B. Frey, The impact of a racing feature on middle school science students' performance in an educational game: the effect of content-free game-actions, Int. J. Game-Based Learn. (IJGBL) 6 (3) (2016) 18-33.

[4] M. Ault, J. Craig-Hare, B. Frey, J.D. Ellis, J. Bulgren, The effectiveness of Reason Racer, a game designed to engage middle school students in scientific argumentation, J. Res. Technol. Educ. 47 (1) (2015) 21-40.

[5] M. Ayalon, R. Hershkowitz, Mathematics teachers' attention to potential classroom situations of argumentation, J. Math. Behav. 49 (2018) 163-173.

[6] R.F. Baumeister, S.J. Scher, Self-defeating behavior patterns among normal individuals: review and analysis of common self-destructive tendencies, Psychol. Bull. 104 (1) (1988) 3-22.

[7] K. Becker, Pedagogy in Commercial Video Games. Games and Simulations in Online Learning: Research and Development Frameworks, Information Science Publishing, Hershey, PA, 2007.

[8] D. Bender-Szymanski, Argumentation integrity in intercultural education: A teaching project about a religious-ideological dialogue as challenge for school, Intercult. Educ. 24 (6) (2013) 573-591.

[9] Y. Bouzid, M.A. Khenissi, F. Essalmi, M. Jemni, Using educational games for sign language learning-a signwriting learning game: case study, Educ. Technol. Soc. 19 (1) (2016) 129-141.

[10] E.A. Boyle, E.W. MacArthur, T.M. Connolly, T. Hainey, M. Manea, A. Karki, et al., A narrative literature review of games, animations and simulations to teach research methods and statistics, Comput. Educ. 74 (1) (2014) 1-14.

[11] A. Bozanta, B. Kutlu, N. Nowlan, S. Shirmohammadi, Effects of serious games on perceived team cohesiveness in a multi-user virtual environment, Comput. Hum. Behav. 59 (3) (2016) 380-388.

[12] D.M. Bressler, A.M. Bodzin, M.S. Tutwiler, Engaging middle school students in scientific practice with a collaborative mobile game, J. Computer Assisted Learn. 35 (2) (2019) 197-207.

[13] B. Cavlazoglu, C. Stuessy, Examining science teachers' argumentation in a teacher workshop on earthquake engineering, J. Sci. Educ. Technol. (2018) 1-14.

[14] S.M. Chang, S.S. Lin, Team knowledge with motivation in a successful MMORPG game team: A case study, Comput. Educ. 73 (1) (2014) 129-140.

[15] Y. Chaudy, T. Connolly, Specification and evaluation of an assessment engine for educational games: Empowering educators with an assessment editor and a learning analytics dashboard, Entertain. Comput. 27 (2018) 209-224.

[16] Y.C. Chen, Y.L. Lu, C.J. Lien, Learning environments with different levels of technological engagement: a comparison of game-based, video-based, and traditional instruction on students' learning, Interact. Learn. Environ. (2019) 1-17.

[17] H.N. Cheng, C.C. Liao, W.C. Chang, iAbstract: game-driven keyword auction and summarization for academic reading, J. Educ. Technol. Soc. 21 (4) (2018) $248-258$.

[18] C.A. Chinn, D.B. Clark, Learning through collaborative argumentation, in: C.E. Hmelo-Silver, C.A. Chinn, C.K.K. Chan, A.M. O’Donnell (Eds.), The International Handbook of Collaborative Learning, Routledge, New York, NY, 2013, pp. 314-332.

[20] D.B. Clark, E.E. Tanner-Smith, S.S. Killingsworth, Digital games, design, and learning: a systematic review and meta-analysis, Rev. Educ. Res. 86 (1) (2016) 79-122.

[21] T.M. Connolly, E.A. Boyle, E. MacArthur, T. Hainey, J.M. Boyle, A systematic literature review of empirical evidence on computer games and serious games, Comput. Educ. 59 (2) (2012) 661-686.

[22] G. Conole, M. Dyke, What are the affordances of information and communication technologies, ALT-J 12 (2) (2004) 113-124.

[23] J. Craig-Hare, M. Ault, A. Rowland, The effect of socio-scientific topics on discourse within an online game designed to engage middle school students in scientific argumentation, J. Educ. Sci., Environ. Health 3 (2) (2017) 110-125.

[24] C. Crawford, The Art of Computer Game Design: Reflections of a Master Game Designer, McGraw-Hill Osborne, 1984.

[25] H. Dehghanzadeh, H. Fardanesh, J. Hatami, E. Talaee, O. Noroozi, Using gamification to support learning English as a second language: a systematic review, Comput. Assisted Lang. Learn. (2019) 1-24.

[26] J. Derboven, B. Zaman, D. Geerts, D. De Grooff, Playing educational math games at home: The Monkey Tales case, Entertain. Comput. 16 (2016) 1-14.

[27] T. Dragon, B.P. Woolf, D. Marshall, T. Murray, Coaching within a domain independent inquiry environment, Lect. Notes Comput. Sci. 4053 (2006) 144-153.

[28] J.E. Driskell, J.D. Dwyer, Microcomputer videogame based training, Educ. Technol. 24 (2) (1984) 11-16.

[29] R. Driver, P. Newton, J. Osborne, Establishing the norms of scientific argumentation in classrooms, Sci. Educ. 84 (3) (2000) 287-312.

[30] S.N. Dvoryatkina, V.S. Karapetyan, A.M. Dallakyan, S.A. Rozanova, E.I. Smirnov, Synergetic effects manifestation by founding complexes deployment of mathematical tasks on the chessboard, Probl. Educ. 21st Century 77 (1) (2019) 8-21.

[31] M.W. Easterday, V. Aleven, R. Scheines, S.M. Carver, Using tutors to improve educational games: A cognitive game for policy argument, J. Learn. Sci. 26 (2) (2017) 226-276.

[33] M. Ebner, A. Holzinger, Successful implementation of user-centered game based learning in higher education: an example from civil engineering, Comput. Educ. 49 (3) (2007) 873-890.

[34] A. Echeverría, C. García-Campo, M. Nussbaum, F. Gil, M. Villalta, M. Améstica, S. Echeverría, A framework for the design and integration of collaborative classroom games, Comput. Educ. 57 (1) (2011) 1127-1136.

[35] F. Fischer, I. Kollar, K. Stegmann, C. Wecker, Toward a script theory of guidance in computer-supported collaborative learning, Educ. Psychol. 48 (1) (2013) 56-66.

[36] J.P. Gee, What video games have to teach us about learning and literacy, Comput. Entertain. (CIE) 1 (1) (2003) 20.
[37] D.H. Goh, R.P. Ang, T.H. Chern, Strategies for designing effective psychotherapeutic gaming interventions for children and adolescents, Comput. Hum. Behav 24 (5) (2008) 2217-2235.

[38] D.L. Gould, P. Parekh, Mentoring and argumentation in a game-infused science curriculum, J. Sci. Educ. Technol. 27 (2) (2018) 188-203.

[39] I. Granic, A. Lobel, R.C. Engels, The benefits of playing video games, Am. Psychol 69 (1) (2014) 66.

[40] C. Herodotou, Mobile games and science learning: A comparative study of 4 and 5 years old playing the game Angry Birds, Br. J. Educ. Technol. 49 (1) (2018) 6-16.

[41] A. Heselmans, B. Aertgeerts, P. Donceel, S. Van de Velde, P. Vanbrabant, D. Ramaekers, Human computation as a new method for evidence-based knowledge transfer in Web-based guideline development groups: proof of concept randomized controlled trial, J. Med. Internet Res. 15 (1) (2013) e8.

[42] W.L. Johnson, H. Vilhjalmsson, S. Marsella, Serious games for language learning: how much game, how much AI? Proceeding of The 2005 Conference on Artificia Intelligence in Education: Supporting Learning through Intelligent and Socially Informed Technology, IOS Press, Amsterdam, The Netherlands, 2005, pp. 306-313.

[43] D.H. Jonassen, B. Kim, Arguing to learn and learning to argue: Design justifications and guidelines, Educ. Tech. Res. Dev. 58 (4) (2010) 439-457.

[44] J. Jung, C. Schneider, J. Valacich, Enhancing the motivational affordance of information systems: The effects of real-time performance feedback and goal setting in group collaboration environments, Manage. Sci. 56 (4) (2010) 724-742.

[45] F. Ke, Designing and integrating purposeful learning in game play: A systematic review, Educ. Tech. Res. Dev. 64 (2) (2016) 219-244.

[46] P.A. Kirschner, G. Erkens, Toward a framework for CSCL research, Educ. Psychol 48 (1) (2013) 1-8.

[47] D.B. Kluver W.M. Robertson R. Agardy, Role playing a city's response to climate change: Engaging undergraduate, 2018.

[48] M. Kordaki, A. Gousiou, Computer card games in computer science education: a 10-year review, J. Educ. Technol. Soc. 19 (4) (2016) 11-21.

[49] D. Kuhn, The Skills of Argument, Cambridge University Press, 1991.

[50] D. Kuhn, A. Crowell, Dialogic argumentation as a vehicle for developing young adolescents' thinking, Psychol. Sci. 22 (4) (2011) 545-552.

[51] Y.W. Lam, K.F.T. Hew, K.F. Chiu, Improving argumentative writing: Effects of a blended learning approach and gamification, Lang. Learn. Technol. 22 (1) (2018) 97-118.

[52] S. Leitão, Evaluating and selecting counter-arguments, Written Commun. 20 (3) (2003) 269-306

[53] K.P. Leith, R.F. Baumeister, Why do bad moods increase self-defeating behavior? Emotion, risk tasking, and self-regulation, J. Pers. Soc. Psychol. 71 (6) (1996) $1250-1267$.

[54] J.C. Lester, H.A. Spires, J.L. Nietfeld, J. Minogue, B.W. Mott, E.V. Lobene, Designing game-based learning environments for elementary science education: a narrative-centered learning perspective, Inf. Sci. 264 (1) (2014) 4-18.

[55] Y.R. Lin, The influences of contextualized media on students' science attitudes, knowledge, and argumentation learning through online game-based activities, J. Computer Assisted Learn. 34 (6) (2018) 884-898.

[56] Q.T. Liu, B.W. Liu, Y.R. Lin, The influence of prior knowledge and collaborative online learning environment on students' argumentation in descriptive and theoretical scientific concept, Int. J. Sci. Educ. 41 (2) (2019) 165-187.

[57] T. Marsh, Serious games continuum: Between games for purpose and experiential environments for purpose, Entertain. Comput. 2 (2) (2011) 61-68.

[58] A. Mathrani, S. Christian, A. Ponder-Sutton, PlayIT: Game based learning approach for teaching programming concepts, Educ. Technol. Soc. 19 (2) (2016) 5-17.

[59] S. McAlister, A. Ravenscroftw, E. Scanlon, Combining interaction and context design to support collaborative argumentation using a tool for synchronous CMC J. Comput. Assisted Learn. 20 (3) (2004) 194-204.

[60] B.M. McLaren, O. Scheuer, J. Mikšátko, Supporting collaborative learning and eDiscussions using artificial intelligence techniques, Int. J. Artif. Intell. Educ. 20 (1) (2010) 1-46.

[61] M. Morveli-Espinoza, J.C. Nieves, A. Possebom, J. Puyol-Gruart, C.A. Tacla, An argumentation-based approach for identifying and dealing with incompatibilities among procedural goals, Int. J. Approx. Reas. 105 (2019) 1-26.

[62] J. Nesbit, H. Niu, Q. Liu, Cognitive tools for scaffolding argumentation, Contemporary Technologies in Education, Palgrave Macmillan, Cham, 2019, pp. 97-117.

[63] O. Noroozi, Considering students' epistemic beliefs to facilitate their argumentative discourse and attitudinal change with a digital dialogue game, Innov. Educ. Teach. Int. 55 (3) (2018) 357-365.

[64] O. Noroozi, H. Biemans, M. Mulder, Relations between scripted online peer feedback processes and quality of written argumentative essay, Internet Higher Educ. 31 (2016) 20-31.

[65] O. Noroozi, P.A. Kirschner, H.J.A. Biemans, M. Mulder, Promoting argumentation competence: Extending from first- to second-order scaffolding through adaptive fading, Educ. Psychol. Rev. 30 (1) (2018) 153-176.

[66] O. Noroozi, S. McAlister, M. Mulder, Impacts of a digital dialogue game and epistemic beliefs on argumentative discourse and willingness to argue, Int. Rev. Res. Open Distrib. Learn. 17 (3) (2016) 208-230.

[67] O. Noroozi, A. Weinberger, H.J.A. Biemans, M. Mulder, M. Chizari, Argumentation-based computer supported collaborative learning (ABCSCL). A systematic review and synthesis of fifteen years of research, Educ. Res. Rev. 7 (2) (2012) 79-106.

[68] J. Osborne, Science education for the twenty first century, Eurasia J. Math. Sci Technol. Educ. 3 (3) (2007) 173-184. 
[69] J. Osborne, Arguing to learn in science: The role of collaborative, critical discourse, Science 328 (5977) (2010) 463-466.

[70] N. Pinkwart, K.D. Ashley, C. Lynch, V. Aleven, Evaluating an intelligent tutoring system for making legal arguments with hypotheticals, Int. J. Artif. Intell. Educ. 19 (4) (2009) 401-424.

[71] P. Pucer, I. Trobec, B. Žvanut, An information communication technology based approach for the acquisition of critical thinking skills, Nurse Educ. Today 34 (6) (2014) 964-970.

[72] M. Qian, K.R. Clark, Game-based Learning and 21st century skills: A review of recent research, Comput. Hum. Behav. 63 (1) (2016) 50-58.

[73] A. Ravenscroft, Designing argumentation for conceptual development, Comput. Educ. 34 (3-4) (2000) 241-255.

[74] A. Ravenscroft, S. McAlister, Digital games and learning in cyberspace: A dialogical approach, E-Learn. Digital Media 3 (1) (2006) 37-50.

[75] A. Ravenscroft, R.M. Pilkington, Investigation by design: Developing dialogue models to support reasoning and conceptual change, Int. J. Artif. Intell. Educ. 11 (1) (2000) 273-298.

[76] A. Reznitskaya, R.C. Anderson, L.J. Kuo, Teaching and learning argumentation, Element. School J. 107 (5) (2007) 449-472.

[77] C. Rosé, Y.-C. Wang, Y. Cui, J. Arguello, K. Stegmann, A. Weinberger, et al., Analyzing collaborative learning processes automatically: Exploiting the advances of computational linguistics in CSCL, Int. J. Comput.-Support. Collabor. Learn. 3 (3) (2008) 237-272.

[78] A. Rowland, J. Craig-Hare, M. Ault, J. Ellis, J. Bulgren, Social media: How the next generation can practice argumentation, Educ. Media Int. 54 (2) (2017) 99-111.

[79] D. Ruggiero, L. Green, Problem solving through digital game design: A quantitative content analysis, Comput. Hum. Behav. 73 (1) (2017) 28-37.

[80] D. Saribas, Z. Gonca Akdemir, Using an innovative tool in science education: examining pre-service elementary teachers' evaluation levels on the topic of wetlands, Int. J. Sci. Educ. 41 (1) (2019) 123-138.

[82] O. Scheuer, F. Loll, N. Pinkwart, B.M. McLaren, Computer-supported argumentation: A review of the state of the art, Int. J. Comput.-Supported Collabor. Learn. 5 (1) (2010) 43-102.

[83] O. Scheuer, B.M. McLaren, F. Loll, N. Pinkwart, Automated analysis and feedback techniques to support and teach argumentation: A survey, in: N. Pinkwart, B.M. McLaren (Eds.), Educational Technologies for Teaching Argumentation Skills, Bentham Science, Sharjah, 2012, pp. 71-124.

[84] Y. Song, J.R. Sparks, Building a game-enhanced formative assessment to gather evidence about middle school students' argumentation skills, Educ. Tech. Res. Dev. (2019) 1-22.

[85] Y. Song, J.R. Sparks, Measuring argumentation skills through a game-enhanced scenario-based assessment, J. Educ. Comput. Res. 56 (8) (2019) 1324-1344.

[86] H.A. Spires, Digital game-based learning, J. Adolescent Adult Literacy 59 (2) (2015) 125-130.

[87] K.D. Squire, M. Jan, Mad City Mystery: Developing scientific argumentation skills with a place-based augmented reality game on handheld computers, J. Sci. Educ. Technol. 16 (1) (2007) 5-29.

[88] C. Steinkuehler, S. Duncan, Scientific habits of mind in virtual worlds, J. Sci. Educ. Technol. 17 (6) (2008) 530-543.

[90] D. Suthers, Representational guidance for collaborative inquiry, in: J. Andriessen, M. Baker, D. Suthers (Eds.), Arguing to Learn: Confronting Cognitions in Computer-supported Collaborative Learning Environments, Kluwer, Dordrecht, 2003, pp. 27-46.
[91] G. Terti, I. Ruin, M. Kalas, I. Láng, A. Cangròs i Alonso, T. Sabbatini, V. Lorini, ANYCaRE: a role-playing game to investigate crisis decision-making and communication challenges in weather-related hazards, Natural Hazards Earth Syst. Sci. 19 (3) (2019) 507-533.

[92] S. Toulmin, The Uses of Argument, Cambridge University Press, Cambridge, UK, 1958.

[93] B. Trilling, C. Fadel, $21^{\text {st }}$ Century Skills: Learning for Life in Our Times, JosseyBass, San Francisco, CA, 2012.

[94] C.Y. Tsai, H.S. Lin, S.C. Liu, The effect of pedagogical GAME model on students' PISA scientific competencies, J. Comput. Assisted Learn. (2019).

[95] T. Van Gelder, Argument mapping with Reason!Able, Am. Philos. Assoc Newsletter Philos. Comput. 2 (1) (2002) 85-90.

[96] F. Vogel, C. Wecker, I. Kollar, F. Fischer, Socio-cognitive scaffolding with computer-supported collaboration scripts: A meta-analysis, Educ. Psychol. Rev. 29 (3) (2017) 477-511.

[97] J.J. Vogel, D.S. Vogel, J. Cannon-Bowers, C.A. Bowers, K. Muse, M. Wright, Computer gaming and interactive simulations for learning: a meta-analysis, $\mathrm{J}$. Educ. Comput. Res. 34 (3) (2006) 229-243.

[98] L.S. Vygotsky, Mind in society: The development of higher mental processes, in: E. Rice, Ed. \& Trans., 1978.

[99] R.C. Wallon, C. Jasti, H.Z. Lauren, B. Hug, Implementation of a curriculum-in tegrated computer game for introducing scientific argumentation, J. Sci. Educ. Technol. 27 (3) (2018) 236-247.

[100] S. Wardani, L. Lindawati, S.B.W. Kusuma, The development of inquiry by using android-system-based chemistry board game to improve learning outcome and critical thinking ability, Jurnal Pendidikan IPA Indonesia 6 (2) (2017) 196-205.

[101] C. Wecker, F. Fischer, Where is the evidence? A meta-analysis on the role of argumentation for the acquisition of domain-specific knowledge in computersupported collaborative learning, Comput. Educ. 75 (2) (2014) 218-228.

[102] A. Weinberger, F. Fischer, A framework to analyze argumentative knowledge construction in computer-supported collaborative learning, Comput. Educ. 46 (1) (2006) 71-95.

[103] C.D. Wilson, F. Reichsman, K. Mutch-Jones, A. Gardner, L. Marchi, S. Kowalski, C. Dorsey, Teacher implementation and the impact of game-based science curriculum materials, J. Sci. Educ. Technol. 27 (4) (2018) 285-305.

[104] K.A. Wilson, W.L. Bedwell, E.H. Lazzara, E. Salas, C.S. Burke, J.L. Estock, C. Conkey, Relationships between game attributes and learning outcomes: Review and research proposals, Simulat. Gaming 40 (2) (2009) 217-266.

[105] B. Woolf, T. Murray, D. Marshall, T. Dragon, K. Kohler, M. Mattingly, M. Bruno, D. Murray, J. Sammons, Critical Thinking Environments for Science Education, IOS, Amsterdam, 2005, pp. 702-709.

[106] P. Wouters, H. Van Oostendorp, A meta-analytic review of the role of instructional support in game-based learning, Comput. Educ. 60 (1) (2013) 412-425.

[107] P. Wouters, C. Van Nimwegen, H. Van Oostendorp, E.D. Van Der Spek, A metaanalysis of the cognitive and motivational effects of serious games, J. Educ. Psychol. 105 (2) (2013) 249.

[108] W.H. Wu, W.B. Chiou, H.Y. Kao, C.H.A. Hu, S.H. Huang, Re-exploring game-assisted learning research: the perspective of learning theoretical bases, Comput. Educ. 59 (4) (2012) 1153-1161.

[109] Y.T.C. Yang, W.C.I. Wu, Digital storytelling for enhancing student academic achievement, critical thinking, and learning motivation: a year-long experimental study, Comput. Educ. 59 (2) (2012) 339-352. 